\title{
Agenda Ambiental na Administração Pública (A3P) como instrumento de gestão de inservíveis em Escola Pública Estadual de Salvador, Bahia
}

The Environmental Agenda in Public Administration (A3P) as a waste management method in a State Public School at Salvador, Bahia

\author{
Leida Baracat de Oliveira', Cristina Maria Dacach Fernandez Marchi", \\ Filipe Ferreira de Almeida Rego"'
}

\section{RESUMO}

\begin{abstract}
A gestão ambiental é fundamental para o desenvolvimento sustentável e deve contemplar cuidados no gerenciamento de resíduos sólidos (RS) gerados em escolas, considerando os instrumentos de políticas públicas para a viabilização desses processos. Este artigo tem como principal objetivo analisar o papel da Agenda Ambiental na Administração Pública (A3P) como contribuição para se pensar a gestão de materiais inservíveis em escolas públicas estaduais, visando obter elementos para práticas sustentáveis. Trata-se de um estudo exploratório, delineado por levantamento fotográfico e observação in loco da disposição e armazenamento de cadeiras e carteiras escolares em uma escola pública. Esta pesquisa documental tem como base legal a Lei no $12.305 / 10$ e como instrumento principal de análise a Cartilha Agenda Ambiental na Administração Pública (A3P), além da Portaria Conjunta SAEB/SEC, $n^{\circ} 036$ de 24 de abril de 2015, que orienta sobre a retirada de bens móveis inservíveis em órgãos públicos. Os resultados apontaram uma gestão ambiental inadequada durante o descarte e a disposição interna de bens móveis escolares. A A3P pode contribuir com elementos para incorporação de princípios sobre responsabilidade socioambiental e práticas ambientais sustentáveis, que incluem a política dos RS e a Educação Ambiental para uma gestão e gerenciamento adequado dos resíduos gerados nas escolas públicas estaduais.
\end{abstract}

Palavras-chave: Gerenciamento de Resíduos Sólidos; Responsabilidade Socioambiental; Educação Ambiental; Carteiras Escolares

\section{ABSTRACT}

Environmental management in solid waste is fundamental for sustainable development. The solid waste generated in schools requires proper care and management to protect the environment. The federal government has a rule for public companies to practice sustainability: the Environmental Agenda in Public Administration (A3P), that is an instrument which includes the proper management of waste generated by public agencies. This paper analyzes the $\mathrm{A} 3 \mathrm{P}$ rule as a contribution to think about the management of waste materials in state public schools, aiming to obtain elements for sustainable school practices. This is an exploratory and bibliographic study based on academic papers, on Brazil federal norms and laws and on behavior description of furniture disposal at one Salvador's public school. It uses photography as a qualitative research tool. The results pointed to an inadequate environmental management of classroom desks and chairs disposal. The application of the A3P could contribute to incorporate principles, responsibility and sustainable environmental practices in Bahia's public schools.

Keywords: Solid Waste Management; Social and Environmental Responsibility; Environmental education; School Furniture

\section{INTRODUÇÃO}

A gestão ambiental adequada dos resíduos sólidos é indispensável nas tomadas de decisóes para o desenvolvimento sustentável na administração pública. Ela pode ser definida como a "... combinação e otimização dos vários recursos disponíveis para alcançar, dentro de parâmetros ambientalmente corretos, os objetivos de: diminuir a geração dos

\footnotetext{
'Biologa, Mestranda em Planejamento Ambiental da Universidade Católica do Salvador (UCSAL), Salvador, BA, Brasil. leidabaractbiologa@gmail.com

" Administradora, Doutora em Geologia,, Professora adjunta da Universidade Católica do Salvador (UCSAL), Salvador, BA, Brasil. cristina.marchi@pro.ucsal.br "' Biomédico, Doutor em Biotecnologia em Saúde e Medicina Investigativa pela Fundação Oswaldo Cruz (FIOCRUZ).Coordenador do curso de Biomedicina da Universidade Católica do Salvador (UCSAL), Salvador, BA, Brasil. filipe.rego@pro.ucsal.br
} 
resíduos, coletá-los, valorizá-los, tratá-los e dar a estes resíduos uma destinação adequada” (AZAMBUJA, 2002, p. 26).

Massukado (2004) considera o termo gestão voltado para a questão dos resíduos sólidos (RS) como "prerrogativa de uma visão ampla do objeto a ser estudado" e o termo gerenciamento, nessa mesma perspectiva, como "a implementação desta visão" (MASSUKADO, 2004, p.4).

O Manual intitulado Bens Inservíveis: logística reversa, meio ambiente e as escolas, desenvolvido pela Secretaria da Educação do Estado do Paraná, orienta a retirada da mobília escolar, tais como cadeiras universitárias e carteiras escolares, quando se tornam "bens inservíveis", ou seja quando não têm mais condiçóes de uso nas escolas e universidade. Assim, esses bens "são recursos que podem ser mais bem reaproveitados ao invés de se proceder com um simples descarte no lixo comum." (PARANÁ, 2015, p. 6). O reaproveitamento, a reutilizaçáo e a reciclagem são conceitos definidos no paragrafo VII - destinação final ambientalmente adequada do art. $3^{\circ}$, Capítulo II da Politica Nacional de Resíduos Sólidos - PNRS (BRASIL, 2010).

Outro regulamento que norteia as açóes ligadas à gestáo ambiental em escolas é a Portaria Conjunta das Secretarias de Administração e de Educação do Estado da Bahia (SAEB/SEC), no 036 de 24 de abril de 2015. Esta Norma dispóe "... sobre os procedimentos para o descarte de carteiras escolares irrecuperáveis no âmbito da Secretaria da Educação do Estado da Bahia e dá outras providências" (BAHIA, 2015, p.4). Carteiras escolares são consideradas no Art. $2^{\circ}$, em seu inciso I como "móvel projetado com a finalidade de assegurar aos alunos uma acomodação adequada para assistir a aula". As carteiras escolares são tidas no inciso II como irrecuperáveis quando "não puderem ser utilizadas para os fins a que se destinam, devido à perda de suas características ou em razão da inviabilidade econômica de sua recuperaçáo". Esta norma considera como descarte, no inciso IV - "a doaçáo sem encargos de carteiras escolares consideradas como irrecuperáveis às cooperativas de reciclagem” (BAHIA, 2015, p.4), tratando-se dos inservíveis.

Em 2008, a Portaria no 217/2008, instituiu o Comitê de Implantação da Agenda Ambiental na Administração Pública - A3P (BRASIL, 2008, p.1), considerando-se que na "busca do desenvolvimento sustentável" os órgãos da Administração Pública têm na "gestão compartilhada da A3P [...] meio para a efetivação da diretriz de transversalidade da Política Nacional de Meio Ambiente - PNMA e do Sistema Nacional de Meio Ambiente - SISNAMA [...]" (BRASIL, Art.. 1º, 2008, p.1)

A Agenda Ambiental na Administraçáo Pública (A3P), desenvolvida pelo Ministério do Meio Ambiente (MMA) trata da "... revisão dos padróes de produção e consumo e a adoção de novos referenciais de sustentabilidade ambiental nas instituiçóes da administraçáo pública” (BRASIL, 2009, p. 33).

A A3P está amparada nos objetivos da Gestão dos Resíduos Sólidos da Política Nacional dos Resíduos Sólidos (PNRS), destacando-se: I- proteçâo da saúde pública e da qualidade ambiental II; - não geração, redução, reutilização, reciclagem [...] disposição final ambientalmente adequada dos rejeitos e VII - gestão integrada de resíduos sólidos. (BRASIL, 2017, Art. 70 , p. 13).

Para Barata, Kligerman e Minayo-Gomes (2007) a criação da A3P é relevante, para a inovação cultural no ambiente de trabalho das instituiçóes, onde o desperdício precisa ser combatido. Chama a atenção, que para o "êxito e efetivaçáo da agenda será decisivo o grau de engajamento do próprio servidor e de seus dirigentes" (BARATA et al., 2007, p.165). Os autores apoiam os objetivos e princípios inseridos na A3P, já que podem contribuir para sensibilizar os gestores públicos quanto às questóes socioambientais. O objetivo principal do Programa A3P é "estimular a reflexão e a mudança de atitude dos servidores para que os mesmos incorporem os critérios de gestáo socioambiental em suas atividades rotineiras". (BRASIL, 2009, p. 33).

A estrutura da A3P se dá em cinco eixos temáticos, a saber: "uso racional dos recursos naturais e bens públicos, gestão adequada dos resíduos gerados, qualidade de vida no ambiente de trabalho, sensibilização e capacitação e licitações sustentáveis." (BRASIL, 2009, p. 36). Ela chama a atenção para a importância da prevenção de danos ambientais, estando de acordo com a Lei 12.305/2010, que institui a Política Nacional de Resíduos Sólidos (BRASIL, 2010)

De acordo com o site do Ministério do Meio Ambiente, a A3P visa "promover e incentivar as instituições públicas no país a adotarem e implantarem [implementarem] açóes na área de responsabilidade socioambiental em suas atividades internas e externas". (BRASIL, 2015). Devido à sua importância foi incluída como "ação integrante do programa de Educação Ambiental para Sociedades Sustentáveis [...] o que garantiu os recursos para a viabilização da sua efetiva implantação e na atividade pública ela se tornou um referencial de sustentabilidade" (BRASIL, 2009, p.30).

Assim, a A3P é uma iniciativa voluntária do governo Federal, que vem a contribuir para essa lacuna de políticas pautadas sustentabilidade. Porém, o seu principal desafio na esfera da própria administração pública reside na promoção da "responsabilidade socioambiental como política governamental [...] os princípios e práticas de sustentabilidade socioambiental seriam o elo de integração entre a agenda de crescimento econômico ao desenvolvimento sustentável” (BRASIL, 2009, p.30). 
No âmbito da educação, o desenvolvimento de um sistema adequado de gestão de inservíveis escolares, que causam transtornos por se constituírem como materiais volumosos, mas que carecem de cuidados para prevenir o descarte, a exemplo das carteiras e cadeiras escolares, precisa ser revisto, entendendo que após o descarte, esses materiais devem ser reaproveitados por Cooperativas de Catadores de Recicláveis.

Esta pesquisa contempla as Metas dos Objetivos de Desenvolvimento do Milênio (ODM), com destaque para o no 12 - "Assegurar padróes de produção e de consumo sustentáveis" (ONUBR, 2015) e em Princípios que nortearam a PNRS, a saber: VII - a responsabilidade compartilhada pelo ciclo de vida dos produtos; VIII - o reconhecimento do resíduo sólido reutilizável e reciclável como um bem econômico e de valor social, gerador de trabalho e renda e promotor de cidadania. (BRASIL, 2017, p.13)

$\mathrm{O}$ descarte de inservíveis escolares de forma inadequada apontou para a importância desta pesquisa, que traz para análise um instrumento como a A3P, a partir também de uma normativa Estadual, que contempla os procedimentos relacionados ao descarte de carteiras escolares, que possa auxiliar gestores (Diretores e Vice-Diretores) nas tomadas de decisóes para a gestão e para o gerenciamento ambientais.

Diante do cenário exposto, é proposta a seguinte pergunta norteadora: a A3P possui elementos que podem aprimorar a gestão de inservíveis, como carteiras e cadeiras escolares, com o proposito de estabelecer práticas sustentáveis em escolas estaduais?

Este estudo tem como objetivo principal analisar o papel da Agenda Ambiental na Administração Pública (A3P) como contribuição para se pensar a gestão de inservíveis em escola pública estadual, visando obter elementos para práticas mais sustentáveis.

\section{METODOLOGIA}

Para expressar o desenvolvimento das práticas de descarte de inservíveis em Unidade Educacional Estadual (UEE) da Bahia, a pesquisa em pauta foi conduzida sob a forma de um estudo de caso em uma escola pública estadual do município de Salvador, Bahia. Trata-se de um estudo exploratório delineado por levantamento fotográfico, observação in loco e estudo documental.

As fontes em que se baseia este estudo permeiam por pesquisas que tem como base legal a Lei no 12.305/10 (BRASIL, 2010), que institui a Política Nacional de Resíduos Sólidos (PNRS). Teve como instrumento principal de análise a Cartilha Agenda Ambiental na Administração Pública (A3P) (BRASIL, 2009) e como documento referencial a Portaria Conjunta SAEB/SEC, no 036 de 24 de abril de 2015, que "dispóe sobre os procedimentos para o descarte de carteiras escolares irrecuperáveis no âmbito da Secretaria da Educação do Estado da Bahia e dá outras providências" (BAHIA, 2015, p.4).

A definição dos tipos de materiais estudados se deu após observação de fotografias tomadas em abril e outubro de 2016, quando foi realizada visitação ao espaço multiuso da escola, onde estavam armazenados os materiais inservíveis. $\mathrm{Na}$ ocasiáo, a área ocupada por esses materiais volumosos, impedia a utilização do local, já que estavam dispostos inadequadamente.

Os dados coletados em 2016, através de registro fotográfico dos inservíveis e que fazem parte do acervo da pesquisa, tiveram autorização da gestáo da escola para serem divulgados.

Com isso, foi possível verificar como os materiais inservíveis, tidos como irrecuperáveis estavam sendo dispostos até serem transportados pela SAEB, após solicitação da direção da Escola. Isso se deu em 25 de outubro de 2016 quando foi gerado o Termo de Baixa de Bens Móveis. (BAHIA, 2016). Este Termo contém informaçóes que permitem uma maior aproximação com a situação documental sobre os encaminhamentos dos resíduos escolares do Estado da Bahia.

De posse das fotografias e da Portaria n036/2015 (BAHIA, 2015), procedeu-se a análise dos dados e informações e as inter-relaçóes com elementos presentes na Agenda Ambiental na Administraçáo Pública.

Finalmente, a partir dos resultados encontrados, o fluxograma sobre procedimentos de descarte de móveis escolares foi desenvolvido.

\section{RESULTADOS E DISCUSSÃO}

Neste item estão apresentados os resultados e discussóes, estruturados da seguinte forma: os Procedimentos para descarte de materiais inservíveis que foram objetos de baixa de retirada pela SAEB e a Responsabilidade Socioambiental e Sensibilização e Capacitação. 


\section{I OS PROCEDIMENTOS PARA DESCARTE DE MATERIAIS INSERVIVEIS QUE FORAM OBJETOS DE BAIXA E RETIRADA PELA SAEB}

O espaço multiuso é um local voltado para atividades esportivas, mas que também pode atender outras demandas como eventos para culminância de projetos da escola. A situação em que se encontravam os bens móveis no espaço multiuso e que seriam objetos de descarte pela SAEB é apresentada na Figura 01.

Figura 01 - Disposiçáo das carteiras escolares e das cadeiras de estudante no espaço multiuso da escola.

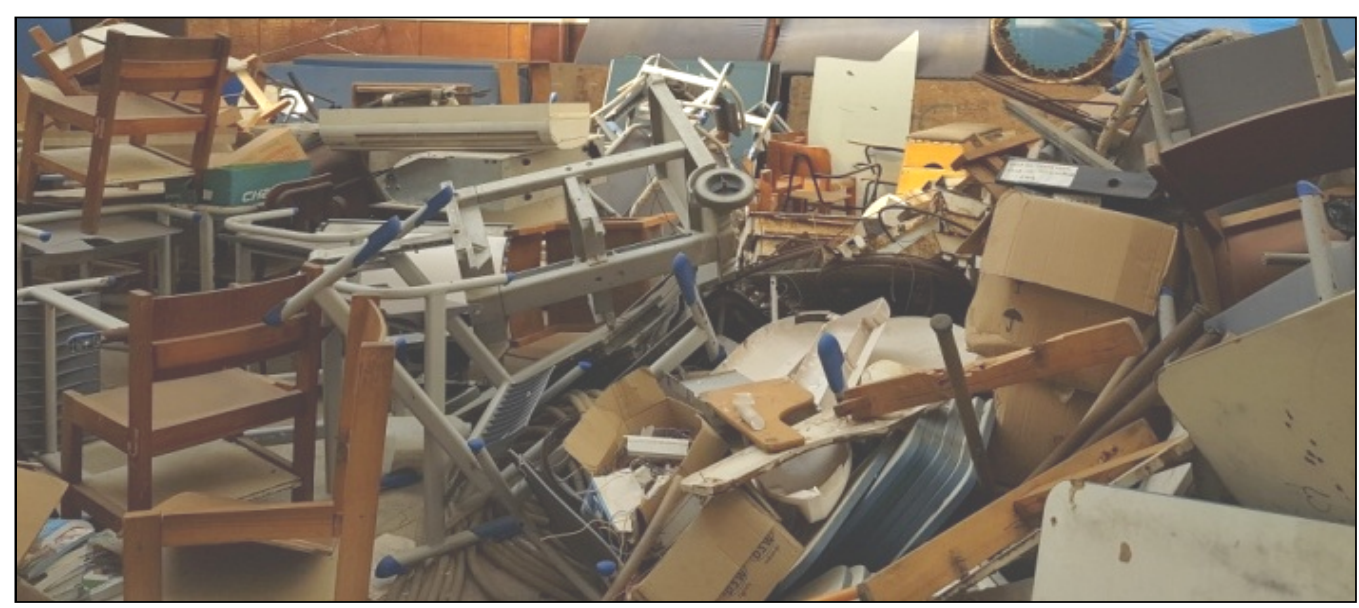

Fonte: Acervo dos autores (2016)

Como primeiro passo para o descarte de materiais inservíveis em escolas, o gestor deve identificar a existência de irrecuperáveis como apresentado na Figura 02.

Figura 02 - Fluxograma: Procedimentos para Descarte de Carteiras Escolares Irrecuperáveis (UEE-BA)

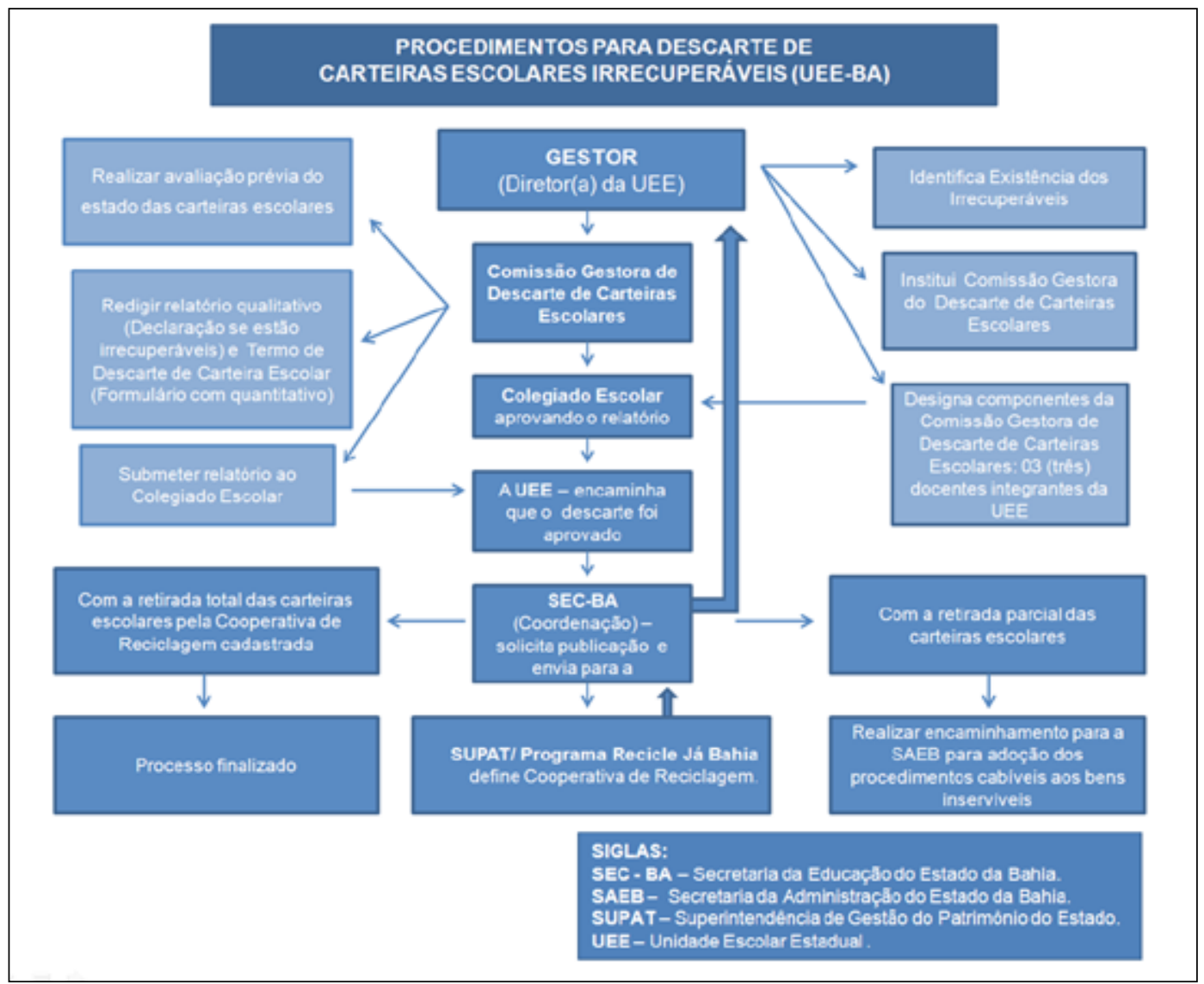

Fonte: Elaboração pelos autores. Construído a partir da Portaria conjunta SAEB/SEC nº 036 de 24 de Abril de 2015 (BAHIA, 2015, p. 4) 
$\mathrm{Na}$ escola em estudo foi observado e registrado, por meio de fotografias, que os inservíveis encontravam-se amontoados, principalmente por cadeiras e carteiras, dispostas em meio a outros materiais (partes de ar-condicionado e de luminárias, dentre outros). Assim, para proceder aos demais passos foi necessária uma organização do espaço. Com isso, foi possível reconhecer quais tipos de materiais tinham sido gerados na escola, ao longo de vários anos e que se encontravam como inservíveis. Finalmente, o cadastramento dos bens móveis foi realizado pela Comissão Gestora de Descarte de Carteiras Escolares, constituída pela Direção da Escola.

Grande parte do mobiliário era de cadeiras de madeira, tombadas, cadeira com encosto e assento em madeira compensada, além de pranchetas que foram encontradas separadas de cadeiras. Modelos mais novos formados pelo "conjunto do aluno" (cadeira e mesa), compostos de tubo de aço, com tampo em MDF, porta livros em polipropileno na cor azul, também se encontravam em meio aos inservíveis.

Essa situação vinha causando transtornos, por ocupar muito espaço. Os resíduos inservíveis se encontravam enferrujados devido ao salitre muito intenso na regiáo da orla marítima de Salvador, onde se localiza a escola. O ambiente se encontrava inadequado, também pelo fato de possuir cobertura de policarbonato translúcido, expondo o material ao calor.

De forma geral, a A3P (BRASIL, 2009, p. 73) preconiza que os materiais móveis descartados podem ser levados para aterros sanitários ou doados às entidades sociais. Certamente, os irrecuperáveis, a exemplo daqueles em estado avançado de ferrugem, devem ser separados e tratados como rejeitos.

Por outro lado, na esfera da Educação, aqueles inservíveis em condições de reaproveitamento (reutilização e reciclagem) devem ser retirados por Cooperativas cadastradas pela SAEB/SEC, como proposto pela Portaria Conjunta SAEB/SEC, no 036/2015 (BAHIA, 2015, p.4). Portanto, neste aspecto a A3P e esta Portaria também estão em consonância, pois tratam de inclusão social.

Com a retirada da maior parte dos materiais do espaço multiuso pela SAEB, em outubro de 2016, foi possível iniciar a reforma e a organização do local para a devida utilização para que foi construído (Figura 03).

Figura 03 - Espaço multiuso, no período de retirada de inservíveis pela SAEB

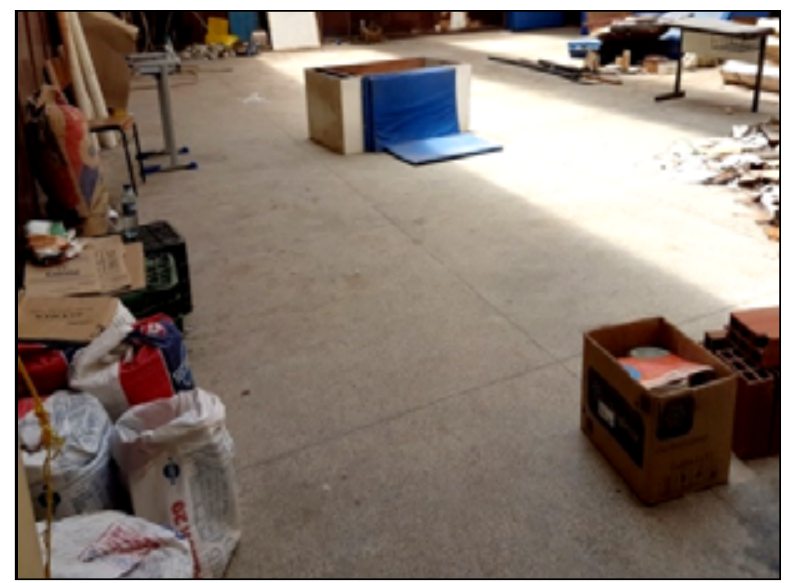

Fonte: Acervo dos autores (2016)

Outro espaço passou a ser utilizado para armazenamento dos resíduos inservíveis. Por meio da implantação da qualidade, organizaçáo e otimizaçáo do espaço, foi iniciado um padrão onde se apontava para uma nova cultura, que necessitava contar com o comprometimento dos gestores, professores, funcionários e alunos, no intuito de promover um ambiente escolar sustentável, ou seja, locais organizados e limpos, asseio e bem estar, fatores que também contribuem para a educação de qualidade. As mudanças de hábitos e padróes de comportamento adequado frente ao meio ambiente necessitam de atividades voltadas para a sensibilização e para a capacitação.

\subsection{Responsabilidade Socioambiental, Sensibilização e Capacitação}

Segundo a A3P a responsabilidade socioambiental na Administração Pública é "um processo contínuo e progressivo de desenvolvimento de competências cidadãs com a assunção de responsabilidades sobre questóes sociais e ambientais relacionadas a todos os públicos com os quais a entidade interage [...]" (BRASIL, 2009, p. 27).

No âmbito da A3P, a Responsabilidade Socioambiental, "se inicia com a decisão da instituição de revisar posturas, atitudes e práticas internas com a finalidade de consolidar a Agenda Ambiental em sua estrutura orga- 
nizacional [...] observando-se que, qualquer instituição da administração pública, de qualquer uma das esferas de governo, pode e deve implantar a A3P." (BRASIL, 2009, p. 86) sendo indispensável promover atividades que sensibilizem e capacite a comunidade.

Nessa perspectiva, para a gestão adequada dos resíduos, de acordo com a A3P é necessário adotar a política dos 5Rs que envolvem as açóes Repensar, Reduzir, Reutilizar, Reciclar e Recusar. No entanto, deve-se priorizar a reduçáo do consumo e também se pensar em "combater o desperdício para só entáo destinar o resíduo gerado corretamente." (BRASIL, 2009, p. 39).

A A3P preconiza que no âmbito da administração pública deve haver a promoção da "responsabilidade socioambiental das suas compras". Isso é importante, segundo ela "para a conservação do meio ambiente [...] mas também [...] relação custo/benefício a médio ou longo prazo quando comparadas às que se valem do critério de menor preço". (BRASIL, 2009, p. 47)

Dentre os caminhos para a implantação de uma A3P, o representante da unidade escolar, como é o caso em questão, poderá assinar um Termo de Adesão ao Programa, que tem como finalidade de "integrar esforços para desenvolver projetos [..]. A assinatura do termo demonstra o comprometimento da instituição com a agenda socioambiental e com a gestão transparente”. (BRASIL, 2009, p. 86)

A A3P também está em conformidade com a Lei 12.305/2010, que dispóe no seu Art. $1^{\circ}$ sobre "[...] as diretrizes relativas à gestáo integrada e ao gerenciamento de resíduos sólidos, incluindo os perigosos, às responsabilidades dos geradores e do poder público e aos instrumentos econômicos aplicáveis". (BRASIL, 2017, p.9) A responsabilidade pela geração dos RS, seja de forma direta ou indireta, está definida pelo Art. $1^{\circ}$, no seu parágrafo $1^{\circ}$. Assim, estão sujeitas à observância dessa Lei pessoas "físicas ou jurídicas, de direito público ou privado, [...] e as que desenvolvam açôes relacionadas à gestão integrada ou ao gerenciamento de resíduos sólidos" (BRASIL, 2017, p.9).

Marchi \& Silva (2018) alertam que a PNRS impóe a elaboração de Plano de Gerenciamento de Resíduos Sólidos (PGRS), instrumento de gestão das organizações públicas e privadas geradoras de resíduos sólidos por meio de suas atividades, nelas incluído o consumo. As autoras advertem que o PGRS “... é um documento técnico que identifica a tipologia e a quantidade de geração de cada tipo de resíduos. Indica as formas ambientalmente corretas para o manejo, nas etapas de geração, acondicionamento, transporte, transbordo, tratamento, reciclagem, destinação e disposição final." (MARCHI \& SILVA, 2018, p. 62).

Contudo, evidenciam-se contradiçóes, pois ao mesmo tempo em que existem instrumentos como a A3P (BRASIL, 2009) e a Lei no 12.305/10 (BRASIL, 2017), que trazem diretrizes para minimização dos problemas relacionados à questáo dos resíduos sólidos, ainda existem espaços da administraçáo pública em áreas urbanas, que náo conseguem superar os seus problemas de descarte, mesmo possuindo regulamentos, normas, portarias e apoio institucional, como é o caso da escola em estudo.

A A3P é uma Norma com muita amplitude, não contempla aspectos específicos como os de unidades escolares, que possuem uma dinâmica própria de funcionamento e de geração de resíduos sólidos. Todas essas questóes postas perpassam pela corresponsabilidade socioambiental dos gestores, do Estado e da comunidade e se constitui numa questão de cidadania.

O planejamento e a gestão pública são discutidos por Limonad (2014), que traz estas ferramentas de gestáo para o âmbito da responsabilidade socioambiental e da sensibilizaçáo sobre inservíveis gerados em escolas. É preciso pensar em mudanças, orientadas a partir de “... açôes transformadoras com efeito cumulativo que permitam superar as questóes localizadas e que contribuam para uma conscientização social na perspectiva de uma sociedade mais equânime [...] o planejamento também pode contribuir nessa perspectiva enquanto instrumento de fortalecimento da cidadania, de emancipação e de consciência social." (LIMONAD, 2014, p. 98).

Aqui se fala do planejamento não verticalizado, "subversivo" como proposto por Randolph (2007, 2008 apud LIMONAD, 2013, p.136), com a participação mais efetiva da sociedade, em que a identificação de suas necessidades e prioridades devem ser respeitadas. Não deve ser diferente nas escolas em regióes metropolitanas, considerando-se, de acordo com Jacobi (2003), a dificuldade para se manter a qualidade de vida nesses grandes centros. Assim, os esforços para a conscientização/sensibilização devem ter como foco central “... o exercício da cidadania e da reformulaçáo de valores éticos e morais, individuais e coletivos, numa perspectiva orientada para o desenvolvimento sustentável." (JACOBI, 2003, p.200).

$\mathrm{Na}$ perspectiva de identificar as necessidades para tomadas de decisóes junto a comunidade escolar e enfrentar as questōes inerentes à gestão dos inservíveis, os gestores das escolas, bem como, de outros setores da administração pública (Federal, Estadual e Municipal), precisam assumir seu papel como planejadores mediadores da responsabilidade socioambiental. 
No âmbito da A3P, enquanto a sensibilização "busca criar e consolidar a consciência cidadã da responsabilidade socioambiental nos servidores [...] a capacitação contribui para o desenvolvimento de competências institucionais e individuais fornecendo oportunidade para os servidores desenvolverem atitudes para um melhor desempenho de suas atividades." (BRASIL, 2009, p. 45).

Esta não é tarefa fácil, e se constitui num grande desafio para a implantação da Agenda, exigindo elaboração de planos de capacitação e formação de comissão gestora. São indicadas pela A3P campanhas de sensibilização e a promoção de ambos os processos, envolvem eventos como palestras e oficinas (BRASIL, 2009).

A Educação Ambiental é fundamental nessa caminhada, por se constituir, segundo a Lei Federal no 9.795/1999, em processo “... por meio do qual o indivíduo e a coletividade constroem valores sociais, conhecimentos, habilidades, atitudes e competências voltadas para a conservação do meio ambiente, bem de uso comum do povo, essencial à sadia qualidade de vida e sua sustentabilidade." (BRASIL, Artigo 1º, 1999).

De acordo com Brasil (2009), a promoção do desenvolvimento sustentável e a necessidade de controle social são diretrizes do Ministério do Meio Ambiente e se constituem em linhas básicas determinantes da Política Ambiental no Brasil. Este Ministério chama a atenção para o fato da necessidade da integração das políticas públicas com o envolvimento dos diferentes setores do Poder Público, porém reconhece que a institucionalização é um processo que requer muito esforço de coordenação desses setores e aponta como estratégias a adoção da "correta aplicaçáo dos instrumentos previstos na legislação até novas formas de atuação como maior transparência e controle social e menor vulnerabilidade aos interesses econômicos e político-partidários." (Brasil, 2009, p.13)

Os desafios são muitos, porém o caminho para soluçóes ou minimização dos problemas referentes aos inservíveis não devem ser impostos pela administração pública, mas devem seguir diretrizes que permitam tomadas de decisões, que garantam a participação efetiva da comunidade escolar nos enfrentamentos dos problemas referentes aos resíduos sólidos de uma forma geral.

A Cartilha A3P traz elementos importantes para sensibilização da comunidade escolar e para a capacitação o pessoal de serviços gerais. Contém nos seus eixos temáticos a coleta seletiva e a reciclagem, aponta para prejuízos ambientais quando o acondicionamento e a coleta são "realizados sem a segregação dos resíduos na fonte, resultam na deterioração, parcial ou total, de várias das suas frações recicláveis" (BRASIL, 2009, p.52).

Nesse sentido, a cartilha A3P reforça que a eficácia da coleta seletiva está na garantia da "correta destinação dos resíduos para empresas que trabalham com reciclagem" e orienta que, para isso é preciso envolver os representantes que atuam nesse sistema, "prefeituras, comunidades, catadores, carroceiros/sucateiros, entidades sociais e, principalmente, empresas privadas que atuem com coleta e reciclagem.” (BRASIL, 2009, p. 53)

Portanto, a responsabilidade compartilhada perpassa pela sensibilização, conscientização, integração da gestão e envolvimento de pessoas para a capacitação e mobilização da comunidade. Todos são responsáveis pela geração de resíduos sólidos. O mais importante é a prevenção e conservação para não geração de rejeitos.

\section{CONSIDERAÇÕES FINAIS}

A análise dos resultados apontou que não existe gestão ambiental, no caso em estudo, voltada para a questão dos materiais inservíveis geradas na escola pública estadual pesquisada, apesar dos esforços para a retirada de grande parte dos resíduos. Contudo, falta definir a melhor forma de acondicionamento e armazenamento dos resíduos inservíveis e daqueles que vem sendo gerados, para um manuseio e descarte seguro e consciente.

Este estudo teve uma pergunta norteadora, que foi se a A3P possuía elementos que poderiam aprimorar a gestão de inservíveis, como carteiras e cadeiras escolares, com o proposito de estabelecer práticas sustentáveis em escolas estaduais. A A3P é um instrumento importante, que está em consonância com a Lei Nacional dos Resíduos Sólidos e que pode auxiliar no atendimento das normativas, devendo ser utilizada por gestores da Escola Pública Estadual para planejarem e, posteriormente, executarem a gestão adequada dos materiais pós-uso. Analisar o papel da A3P, inter-relacionando esta Agenda com a gestão dos materiais pós-uso gerados em uma escola pública estadual de Salvador, Bahia, foi o objeto desta pesquisa. Possibilitou um melhor entendimento do funcionamento do gerenciamento escolar de resíduos inservíveis e apontou elementos que orientam para o correto manejo de resíduos escolares. A incorporação de elementos como doação, reciclagem, inserçáo de entidades sociais, e cooperativas de materiais recicláveis e reaproveitáveis como orientados na A3P, colocaria a escola no caminho para construção de um espaço educacional que destaca o desenvolvimento de práticas mais sustentáveis.

É importante destacar que a responsabilidade socioambiental é fundamentada por atividades ligadas à sensibilização e à capacitação da comunidade e a Educação Ambiental se torna preponderante nesse processo. 
As escolas devem prezar pela manutenção dos bens móveis para evitar gerar mais materiais pós-uso de forma que outras geraçóes também possam usufruir de seus benefícios, dando maior ênfase às cadeiras e carteiras, que se constituem em materiais volumosos.

Algumas limitações deste estudo devem ser consideradas, como a impossibilidade dos pesquisadores em terem acesso aos documentos que detalham a destinação final dos resíduos retirados na escola, de forma a possibilitar maior compreensão das açôes desenvolvidas no lócus da pesquisa. Conhecer melhor a dinâmica do fluxo desses materiais nos diferentes ambientes da escola, considerando inclusive a sazonalidade. Ampliaria este estudo a observação de diferentes unidades escolares com suas diferentes demandas. É preciso conhecer outras realidades e dar mais visibilidade para o problema.

Assim, sugere-se a agenda ambiental específica para a gestão dos resíduos sólidos gerados em escolas, com diretrizes que norteiem procedimentos para gerenciamento adequado dos materiais descartados, para atender as diversas demandas diante das realidades em que se apresentam os diversos espaços escolares, a exemplo do uso consciente da água e da energia elétrica. O desenvolvimento de um instrumento específico para escolas, que possibilite à comunidade pensar em práticas sustentáveis contextualizadas, sendo interessante a formaçáo de uma "rede A3P escolar" no apoio de práticas sustentáveis.

\section{REFERÊNCIAS}

ASSOCIAÇÃO BRASILEIRA DE NORMAS TÉCNICAS - ABNT. NBR 10.004: Resíduos sólidos: classificação. Rio de Janeiro: ABNT, 2004. Disponível em: http://www.ebah.com.br/content/ABAAAfRNMAB/nbr-10004-residuos-solidos-classificacao Acesso em: 17 set. 2017.

AZAMBUJA, Eloisa Amábile Kurth de. Proposta de Gestáo de Resíduos Sólidos Urbanos: análise do caso de Palhoça/ SC. 2002. Dissertação (Mestrado em Engenharia) - UFSC, Florianópolis, 2002. p. 26. Disponível em: http://www. bvsde.paho.org/bvsacd/ cd48/11214.pdf. Acesso em: 16 de set de 2017

BAHIA. Governo do Estado da Bahia. Termo de Baixa de Bens Móveis. Tipo de Baixa: Almoxarifado Central. Destinatário: SAEB. 25.08.2016

BAHIA. Portaria Conjunta SAEB/SEC no 036 de 24 de abril de 2015. Dispóe sobre os procedimentos para o descarte de carteiras irrecuperáveis no âmbito da Secretaria da Educação do Estado da Bahia e dá outras providências. Diário Oficial do Estado da Bahia, Disponível em: http://dovirtual.ba.gov.br/egba/reader2/. Acesso em: 16 mai. 2018 às $11 \mathrm{~h} 55 \mathrm{~min}$.

BARATA, Martha Macedo de Lima; KLIGERMAN, Débora Cynamon; MINAYO-GOMEZ, Carlos. A gestão ambiental no setor público: uma questão de relevância social e econômica. Ciênc. saúde coletiva [online]. 2007, vol.12, n.1, pp.165-170. ISSN 1413-8123. Disponível em: http://dx.doi.org/10.1590/S1413-81232007000100019. Acesso em: 20 mar. 2018, 20:30

BRASIL. Lei no ${ }^{\circ}$ 12.305, de 2 de agosto de 2010. Política Nacional de Resíduos Sólidos.Brasília: Câmara dos Deputados, Ediçôes Câmara, 2017. Disponível em: file:///C:/Users/Leda/Downloads/politica_residuos_solidos_3ed.reimp.pdf. Acesso em: 20 mar. 2018 às $20 \mathrm{~h} 47 \mathrm{~min}$.

BRASIL. Ministério do Meio Ambiente. Agenda Ambiental na Administraçáo Pública (A3P). 2015?. Disponível em: http://www.mma.gov.br/mma-em-numeros/a3p. Acesso em: 27 ago. 2017.

BRASIL. Ministério do Meio Ambiente. A3P - Agenda Ambiental na Administração Pública. Cartilha, 5a edição, Brasília. 2009. Disponível em: http://www.mma.gov.br/estruturas/a3p/_arquivos/cartilha_a3p_36.pdf. Acesso em: 27 ago. 2017.

BRASIL. Portaria No 217, de 30 de julho de 2008. Considerando que a Agenda Ambiental na Administração Pública - A3P propõe a inserção de critérios socioambientais na gestão dos serviços públicos em todos os níveis de governo. 2008. Disponível em:http://www.mma.gov.br/estruturas/a3p/_arquivos/36_09102008033030.pdf. Acesso em: 28 set. 2017. 
BRASIL. Lei no 9.795, de 27 de abril de 1999. Dispóe sobre a educação ambiental, institui a Política Nacional de Educação Ambiental e dá outras providências. Disponível em: http://www.planalto.gov.br/ccivil_03/leis/L9795.htm Acesso em: 01 ago. 2017.

JACOBI, Pedro. Educaçáo ambiental, cidadania e sustentabilidade. Cadernos de Pesquisa. São Paulo: Autores Associados, n. 118, p. 189-205, 2003.

LIMONAD, Ester. Um novo planejamento ou um novo estado para um novo Brasil? In: LIMONAD, Ester; CASTRO, Ramos Edna. Um novo planejamento para um novo Brasil? Rio de Janeiro: LetraCapital, 2014, p. 80-118

LIMONAD, Ester. A insustentável natureza da sustentabilidade. Da ambientalizaçáo do planejamento às cidades sustentáveis. Cadernos de Metrópole.[online]. São Paulo: PUC-SP, jan/jun 2013, v. 15, n. 29, PP. 123-142. Disponível em: https://revistas.pucsp.br/index.php/metropole. Acesso em: 01 nov 2017.

MASSUKATO, Luciana Miyoko. Sistema de Apoio à Decisão: avaliaçâo de cenários de gestáo integrada de resíduos sólidos urbanos domiciliares. 2004. p. 42. Dissertação (Mestrado em Engenharia Urbana)-Universidade Federal de São Carlos, São Carlos:UFSCar, SP, 2004. 230p. Disponível em: http://www.bvsde.paho.org/bvsacd/iswa2005/sistema.pdf. Acesso em: 21 mai. 2018 21:41.

MARCHI, Cristina Maria Dacach Fernandez; SILVA, Mayara. Elaboraçáo dos Planos de Gerenciamento de Resíduos Sólidos: Apoio à Gestáo Pública. In: MARCHI, Cristina Maria Dacach Fernandez. Gestáo dos Resíduos Sólidos: conceitos e perspectivas de atuação, 1. ed., Curitiba: Appris Ltda, 2018.

ONUBR - Naçôes Unidas no Brasil. Objetivos de Desenvolvimento sustentável. Transformando Nosso Mundo: A Agenda 2030 para o Desenvolvimento Sustentável. Disponível em:https://nacoesunidas.org/wp-content/uploads/2015/10/agenda2030-pt-br.pdf. Acesso em: 06 set. 2017.

PARANÁ. Secretaria de Estado da Educação. Bens Inservíveis: logística reversa, meio ambiente e as escolas. Paraná, 2015, p.6. Disponível em:http://www.gestaoescolar.diaadia.pr.gov.br/arquivos/File/pdf/gestao_residuos_inserviveis.pdf Acesso em: 18 out. 2017. 